\title{
Rope Pump Modifications to Reach Greater Depths: A Service Project for Clean Water in The Gambia
}

\author{
Jennifer Kadlowec \\ Professor, Department of Mechanical Engineering \\ Rowan University \\ Glassboro, NJ 08028 \\ kadlowec@rowan.edu \\ Jess Everett \\ Professor, Department of Civil and Environmental \\ Engineering \\ Glassboro, NJ 08028 \\ everett@rowan.edu \\ Hong Zhang \\ Associate Professor, Department of Mechanical Engineering \\ Rowan University \\ Glassboro, NJ 08028 \\ zhang@rowan.edu \\ Taylor Purdue \\ Undergraduate Senior, Dept. of Mechanical Engineering \\ Rowan University \\ Glassboro, NJ 08028
}

\author{
Katelyn Dmitruck \\ Undergraduate Senior, Dept. of Civil and Environmental \\ Engineering \\ Rowan University \\ Glassboro, NJ 08028 \\ Kevin Ketcho \\ Undergraduate Senior, Dept. of Mechanical Engineering \\ Rowan University \\ Glassboro, NJ 08028 \\ Kyle Pillion \\ Undergraduate Senior, Dept. of Mechanical Engineering \\ Rowan University \\ Glassboro, NJ 08028 \\ Dan Bounieav \\ Undergraduate Senior, Dept. of Mechanical Engineering \\ Rowan University \\ Glassboro, NJ 08028
}

Abstract - Rope pumps are a locally adaptable and relatively simple technology for water retrieval that are easy to understand and repair and perform well with respect to water quality. Concern Universal - an NGO with offices in Banjul, The Gambia - was introducing the rope pump into The Gambia and needed assistance in designing a rope pump that could lift water from greater depths. Modifications to the rope pump would be needed, which became the basis of an opportunity for a student service-learning project / capstone design experience for students to develop a solution. More specifically, the design criteria were to develop an affordable, easy to use rope pump that could be used to pump water from a depth of $30 \mathrm{~m}$ to a storage tank $5 \mathrm{~m}$ above ground with a constraint of human power by a single operator. A team of undergraduate students and faculty designed, built and tested a rope pump that was similar to those used in rural Gambian villages. The team's rope pump design, analyze, build and test process is described in this paper. The design solution began by first modeling the rope pump in a user-defined MATLAB routine to effectively determine the effects of parameters and constraints. A parametric study, where pipe diameter, number of pistons per meter of rope length, well depth and input rotational speeds were varied, was conducted. These results provide a range of conditions for using a rope pump at various depths and provided a basis for designing a pump. Experimental tests were conducted, and the results were compared to theoretical predictions. Experimental results for flow rate were within 3-18\% of predicted values. To meet the client's needs, it was determined that a rope pump with $1.27 \mathrm{~cm}(0.5$ in) diameter piping, two pistons per meter, and a belt drive with gears of ratio of 1.5:1 to increase 
torque could raise water $35 \mathrm{~m}$ using operator under human-power. Additionally, alternative forms of power that would be available to the region are briefly investigated and discussed as potential future work, although further development was beyond the scope of this design project.

Index Terms - Africa, Engineering Design, Human Powered Pump, Rope Pump, Water Supply

\section{INTRODUCTION}

\section{Background about rope pumps}

Rope pumps were first used in ancient China over 2000 years ago. A typical rope pump can be seen in Figure 1. A rope fitted with pistons (washers) travels from the bottom of a well inside a pipe, then around a wheel (pulley) at the top to return to the bottom. The pulley is rotated by hand using a crank. As the pistons are pulled through the pipe they force water to the surface like a series of endless yet leaking buckets. As long as the pistons fit the pipe correctly, they can lift a significant amount of water. A small gap between the outer diameter of the piston and the inside diameter of the pipe exists of $0.5 \mathrm{~mm}$ to $1.0 \mathrm{~mm}$. ${ }^{\mathrm{i}}$ The friction between the piston and the pipe will be small for easy operation and the water leakage from the gap will be minimal so the majority will be transported to the output. Typical designs space the pistons anywhere from 0.7 $\mathrm{m}$ to $1.0 \mathrm{~m}$ along the rope.

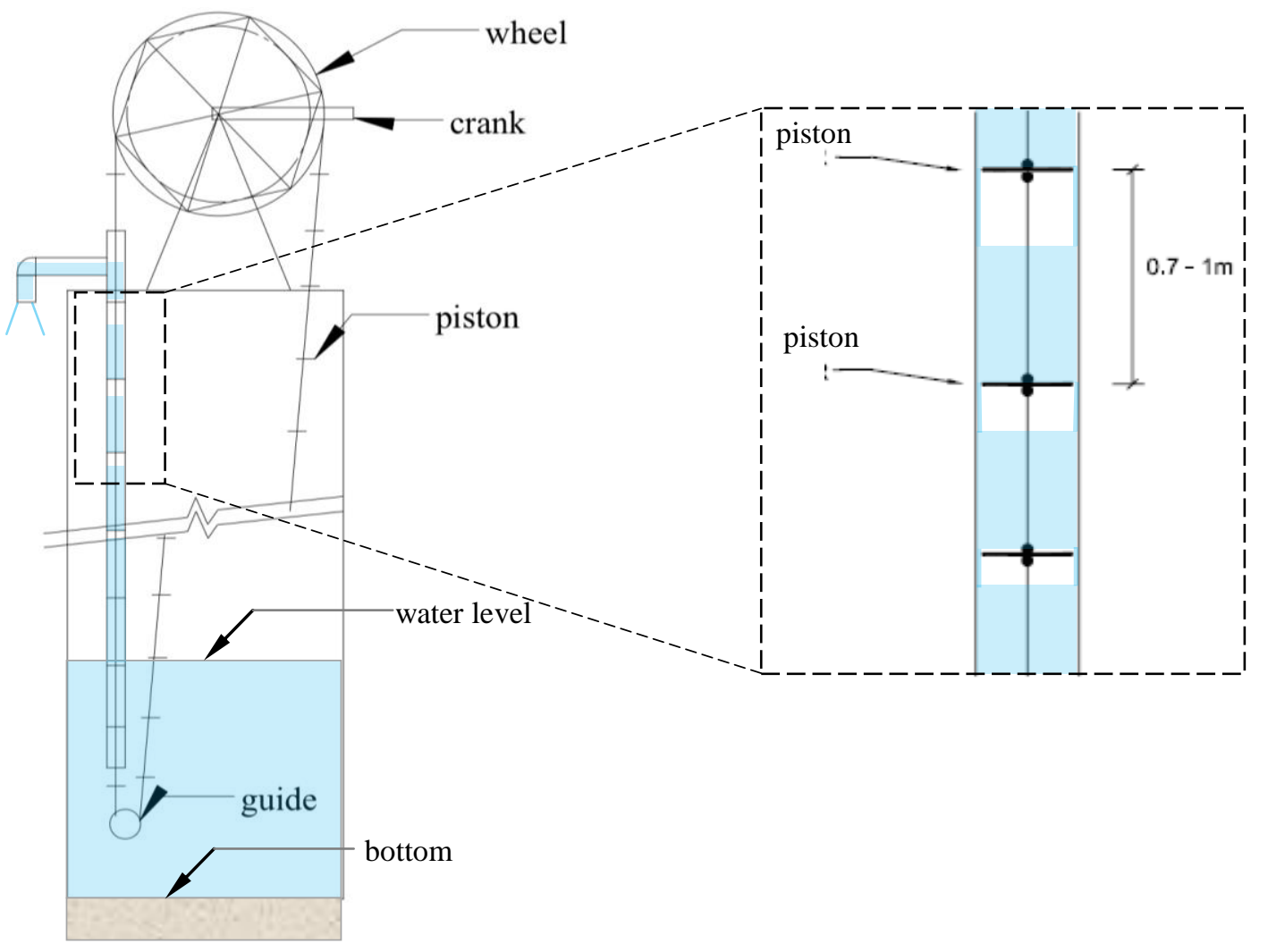

FIGURE 1

CROSS-SECTION OF A ROPE PUMP WITH PISTONS LIFTING WATER IN PIPE 
In the 70s, rope pumps were "rediscovered" using PVC pipes and metal pulleys, and introduced in Africa as the 'Rope and washer pump', a low lift pump for irrigation and family wells. It did not take off, probably because of its low lift capacity, "medieval" image, and a lack of involvement from the local private sector. This changed in 1986 when a Dutch organization improved the design and disseminated it in Central America. The rope pump provides over 35\% of the rural water supply in Nicaragua. ${ }^{\text {ii }}$ Local adaptability is a strong point of the modern rope pump, since it is a relatively simple technology that is easy to understand and repair, unlike more sophisticated hand pumps or submersible electric pumps. One study even shows that rope pumps outperform hand pumps with respect to water quality. ${ }^{\text {iii }}$

Four million people use an estimated 100,000 rope pumps worldwide. Numbers may be higher since not all rope pump producers and Non-Governmental Organizations (NGOs) report

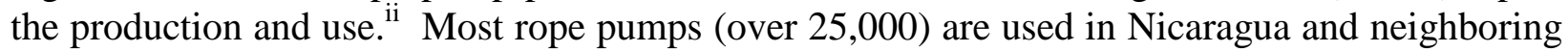
countries; a large number used in Africa, of which some 5,000 are in Zimbabwe and Malawi [The Elephant Pump], 2,000 in Ghana [Victoria pump], 2,000 in Ethiopia and 3,000 in Zambia, Tanzania, Mozambique, Madagascar; and some used in Asia (Cambodia and India). ${ }^{\text {iv }}$

\section{Rowan University and Rope Pumps}

An interest in rope pumps at Rowan University was generated at the intersection of the active Rowan Engineers Without Borders (RU EWB) club, the US EPA P3 grant program, and the Rowan Engineering Clinic curriculum. The EWB club at Rowan has been active since 2003, conducting projects in Honduras, El Salvador, Thailand, Senegal, The Gambia, and South Dakota. ${ }^{v}$ Many of the RU EWB projects focus on water supply, leading to an interest in sustainable technologies such as the rope pump. The US EPA P3 program funds student projects that help people, planet, and prosperity. Many P3 projects are focused on sustainable technologies for the developing world. The Rope pump was seen as likely candidate for P3 funding. Additionally, this project would provide an excellent opportunity for a service learning experience in the Junior-Senior Engineering Clinic for students to design and develop the solution. Briefly, the Rowan Engineering Clinics are an eight-semester sequence of courses that introduce students to measurement, reverse engineering, design, research, report writing, presentation, etc. By the time they are juniors, Rowan Engineering students are able to contribute to real world research and applied engineering projects. The Junior-Senior Clinic is typical of a capstone design experience, where students have four semesters that in Mechanical Engineering involve "design, build, analyze and test". Projects are typically multidisciplinary and span design competitions, sponsored industry and government contracts and research, humanitarian interests or student proposed entrepreneurial ideas. Teams of three to five students work on the projects under the guidance of one or two faculty members. Often students choose to continue a project for two semesters to span an academic year, yet each semester involves design of a product or experiment with deliverables of mid-semester and final presentations as well as a final design report.

Students in an EWB Junior-Senior Clinic were asked to generate ideas for P3 proposals. Three ideas were identified that led to the submission of proposals in 2009: Rope Pumps, Peanut Shell Fuel, and Sewage Heat Recovery. The Peanut Shell Fuel project, initially proposed by a Sophomore Clinic team writing a hypothetical proposal for a course assignment, then reworked and proposed to the EPA P3 program by a Junior-Senior Clinic Team, was funded. The Rope pump and Peanut Shell Fuel projects were inspired by needs in The Gambia, where the RU EWB 
chapter had a project at the time. In researching for the P3 Proposal, students discovered that Concern Universal - an NGO with offices in Banjul, The Gambia - was introducing the rope pump into The Gambia. Though the Rope Pump project was not funded, students met with Paul Johnson, Concern Universal Rope Pump coordinator, during the next EWB trip to The Gambia in January 2010 and discussed a Rope Pump project.

Paul Johnson asked for help in designing a rope pump that could lift water from greater depths such as $30 \mathrm{~m}$ below into a storage tank $5 \mathrm{~m}$ above ground level, thus a total of 35 meters. Rope pump modification was needed to easily lift water from wells at greater depths such as through gearing. This became the basis of an opportunity for a student service-learning project through the Junior-Senior Engineering Clinic for students to develop a solution.

Rope pump performance has been evaluated in developing areas, but as mentioned, a limitation is that standard rope pumps have been typically used at shallow depths. ${ }^{\mathrm{vi}}$ While advances were made in Nicaragua in 1984 to include the use of rubber washers ${ }^{\text {vii }}$ and double cranks $^{\text {viii }}$ to increase the operating depth, the team worked within the constraints of a standard rope pump design with a single operator as requested by NGO partner Paul Johnson.

The purpose of this work is to 1) briefly discuss the rope pump design, 2) parametrically study the design space using a rope pump model by Smulders and Rijs ${ }^{\text {ix }}$ for various pump heights and number of pistons, 3) compare theoretical and experimental flow rate results and 4) determine capability and provide guidance in order to reach a depth of 35 meters with a standard rope pump operated by a single operator using human power as requested by the client and NGO partner.

\section{Methods ANd Design Process}

\section{Theoretical Modeling of Rope Pump:}

In order to find an optimized design for a rope pump, the group produced a user-specified MATLAB code using a rope pump model developed by Rijs and Smulders ${ }^{\text {ix }}$, with key equations summarized below. This model describes how water flows in a pipe powered by pistons attached to a rope; and allows the power and speed inputs to be determined that are necessary to operate the pump. Several equations derived in this model are most relevant to the project goals to lift water 35 meters. One key variable is the critical velocity, $\mathrm{V}_{\mathrm{c}}$, of the pistons. If the piston speed is slower than $\mathrm{V}_{\mathrm{c}}$, then all the water in each section will be leaked down through the piston gap before it reached the outlet. Assuming no friction between water and the wall, this velocity is dependent upon the thickness of the gap, $t$, between the pipe wall and the pistons edge; the depth of the pipe, D; the height of each unit, which is related to the number of pistons per unit length, $\mathrm{N}$; and the acceleration of gravity, g; in Equation 1.

$$
V_{c}=\frac{4 \times t}{D} \times \sqrt{\frac{2 \times g}{N}}
$$

Next the team needed to calculate the ideal flow rate of the rope pump, $\phi_{\text {id }}$, which is the product of the area of the pipe, $A$, and the translational speed of the pistons, $V_{p}$, in the pipe in Equation 2. Note that $V_{p}$ is equal to the rotational speed of the wheel multiplied by the wheel 
radius. This will give the flow rate of the pump assuming that the entire pipe is filled with water and there are no losses around the piston or leakage from the pipe.

$$
\phi_{i d}=V_{p} \times A
$$

Once the ideal flow rate is found, it is possible to calculate the power, $\mathrm{P}_{\mathrm{n}}$, needed to operate the pump by multiplying by the weight of the column of water, where $\mathrm{H}$ is the height difference between the inlet and outlet of the riser pipe Equation 3.

$$
\begin{array}{ll}
P_{n}=\rho \times g \times H \times \phi_{i d} & \text { Eq. } 3
\end{array}
$$

The final step taken to predict the performance of the rope pump was to calculate the leakage flow rate, Equation 4, and from that the actual flow rate from the output spout. The actual flow rate is the difference between the ideal flow rate and the leakage flow rate, $\phi_{\mathrm{L}}$. The leakage flow rate is approximated by

$$
\phi_{L}=\pi \times t \times D \times \sqrt{\frac{2 \times g}{N}} \quad \text { Eq. } 4
$$

Some assumptions are made to obtain these simple calculations. First, the pistons and pipes are assumed to be uniform. This is so that the gap between the pipe wall and the piston can be considered constant around the circumference of the piston and is the same for each piston. Second, the input rotational speed is assumed constant, though in practice this is difficult to achieve in human-powered devices. Viscous and hydrodynamic friction effects are not considered. Also, the volumes of the pistons and rope are considered to be negligible compared to the total volume of the pipe. Finally, a maximum power input of $100 \mathrm{~W}$ assumed. For simulation purposes leg power was the focus, because this larger power (as opposed to hand cranking) would be necessary to achieve a greater depth with human power.

Experimentation and research were used for determination of human generated power levels. The team went to the University's Recreation center in order to use a hand crank and recumbent bicycle machine to find the power produced by the cycling motion of the arms and legs respectively. Three adult males were asked to crank the machine at a comfortable, sustainable pace for one minute. During the time period the rotation speed and the power were recorded from the machine display screen. The process was repeated 3 times for each person. The values were reduced by $20 \%$, resulting in $50 \mathrm{~W}$ as an estimate of power production by women or older children, who would be typically using the rope pump. Similarly, to find the power produced by legs, the team had one person pedal the recumbent bike for two minutes for three tests. On each of the three tests the resistance was held constant and the biker held a leisurely pace, a medium pace, and a pace at the upper limit of what was considered comfortable 60,80 and $100 \mathrm{~W}$, respectively). These are comparable to sustainable (15 min.) human power performance levels of 40 to $50 \mathrm{~W}$ for arm and 70 to $90 \mathrm{~W}$ for leg power, respectively at preferred crank cadences of 30 to $50 \mathrm{rev} / \mathrm{min}$ that result in 30 to $50 \mathrm{~W}$ pump performance for micro-irrigation. ${ }^{\mathrm{vi}}$

The model equations including the above assumptions were written into a user-specified MATLAB code where each variable was calculated and output to an excel sheet. A parametric study was conducted where the depth values were 25,35 and $45 \mathrm{~m}$, the pipe diameter varied 
from 1.27 to $2.54 \mathrm{~cm}$ and the input rotational speed of the wheel from 40 to $80 \mathrm{RPM}$. This resulted in piston velocities of 0.71 to $1.41 \mathrm{~m} / \mathrm{s}$. The piston spacing was varied at 1 and 2 pistons per meter. Equation 1 was used to find the critical velocity. The piston velocity, $\mathrm{V}_{\mathrm{p}}$ was varied between 1.5 times greater than $\mathrm{V}_{\mathrm{c}}$ to 2.5 times greater than $\mathrm{V}_{\mathrm{c}}$, in increments of 0.5 . The ideal flow rate was calculated for each of the varied parameters using Equation 2. The power was calculated which provided the information necessary to calculate the torques and rotational velocities necessary to operate the pump. Finally, the actual flow rate was found by taking the difference of Equations 2 and 4. By assessing the effects of parameters on the power and flow rate, working design combinations could be determined. In some cases, generating more force to lift water with the pistons at the expense of a decrease in rotational speed of the wheel would result in a feasible solution.

\section{Experimental Study:}

Tests were conducted with a prototype rope pump built at Rowan University College of Engineering by a team of Junior and Senior Engineering students. The team used a manual published by the Gaia movement ${ }^{\mathrm{x}}$ to guide the construction of a rope pump, which was presented and reported as course deliverables. ${ }^{\text {xixii }}$ The components and fabrication supplies and methods closely matched those in The Gambia. Supplies could be attained or fabricated there and the team considered the ease of building and maintenance. The first rope pump built and tested -consisting of a wheel, crank, base, pistons, guide, pipe, rope, and platform -- is briefly described here. A rubber tire was used to make the wheel $(34 \mathrm{~cm}$ dia.) by cutting the sidewalls, reverse stapling the sides together and making spokes from rebar. A steel tube was bent to make a crank (0.5 m dia.), which was connected to the wheel by a student machined axle lock. The wheel assembly was connected to a base with welded rebar rods. Sample pistons were acquired from Paul Johnson of Concern Universal, which had been fabricated locally in Africa. The students designed similarly shaped pistons using the solid modeling software SolidWorks and fabricated them out of high-density polypropylene using a 3D printer (Stratasys). A ceramic guide cylinder is placed at the bottom of the well (in our case a large barrel) to guide the rope and pistons and extend rope life. The students molded clay for the guide cylinder that was fired in a kiln operated by the University Art Department. Polypropylene rope and PVC plumbing pipe and fittings $(1.27 \mathrm{~cm}$ and $2.54 \mathrm{~cm}$ diameter) were purchased from a home improvement store. Finally, the pump was mounted on a platform attached to a wall and ceiling measuring

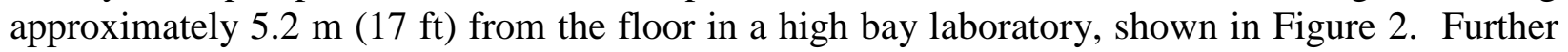
improvements included a second return spout for overflow water out of the top of the pump and also a new platform to move the pump to a fourth floor stairwell $15.5 \mathrm{~m}(51 \mathrm{ft})$ from the floor. This was the highest platform available on campus for testing. The students also designed and built a belt drive with gears at a ratio of 1.5:1 to increase the torque needed to lift water from greater depths at the expense of decrease piston velocity. 

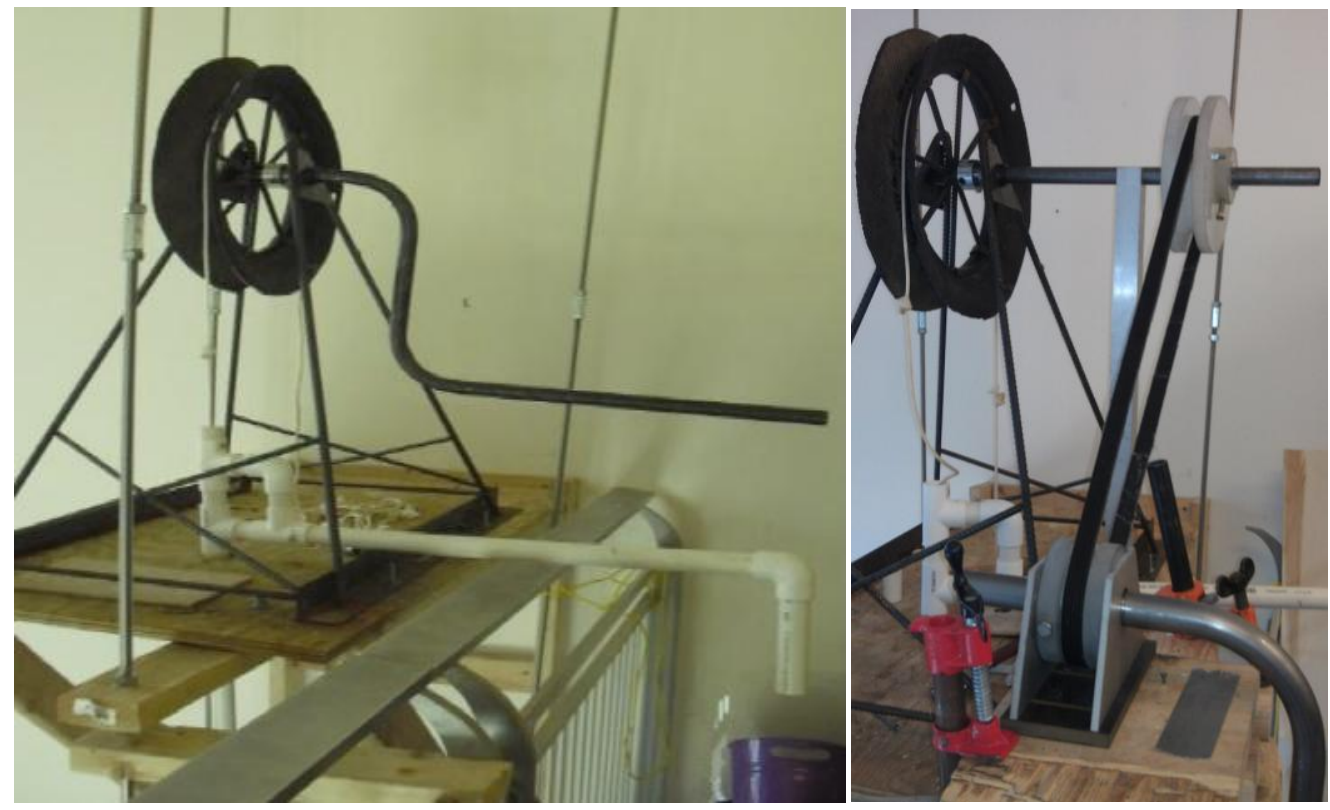

FIGURE 2

\section{ROPE PUMP PULLEY ON PLATFORM AT 5.2 M (17 FT ${ }^{\text {xiii }}$ SHOWN WITHOUT AND WITH GEARS}

To compare experimental results with theoretical predictions, the parameters that were studied were the pipe diameter, piston spacing, and input rotational speed of the wheel. The pump was initially mounted to a platform $5.2 \mathrm{~m}$ above the ground. A barrel (55 gallon drum) of water at ground level was filled with water. The rope pump was set up with $1.27 \mathrm{~cm}$ diameter pipe and pistons spaced $0.5 \mathrm{~m}$ apart. Using the $0.5 \mathrm{~m}$ lever arm, one member of the team rotated the crank between 40 and 50 RPM. The timer began recording the time when water began to flow from the output spout and into a bucket that was placed beneath it. After one minute of flow the cranking would stop and flow would slowly come to a stop. The volume of water was measured using $2 \mathrm{~L}$ beakers and a $1000 \mathrm{~mL}$ graduated cylinder. Each set of test conditions was repeated, and the results were averaged.

The water was reused by returning it to the barrel below located at ground level. The experiment was repeated for a faster RPM value, 50-60 RPM and once again for 60-70 RPM. Each experiment was then replicated so an average value could be found for flow rate. The experiment was then set up for the $2.54 \mathrm{~cm}$ diameter pipe and the entire process was repeated. The platform was then mounted with the pump at $15.5 \mathrm{~m}$. Experiments were conducted, and then the gears and belt were used to test conditions of decreased rotational speed and increased torque to lift the water with the pistons. 


\section{RESULTS}

A theoretical model was used to predict the power needed for the depths of 25, 35 and $45 \mathrm{~m}$, various pipe diameters and piston spacing of 1 or 2 per meter. Comparisons of the required input power are shown in Figure 3. As expected, power requirements increase as 1) pipe diameter increases or 2) well depth increases. Piston spacing also plays a role in the flow rate and power requirement. The model predicts that the flow rate is slightly greater for the same pumping power with two pistons per meter than for one piston per meter. This is also expected based on Equation 4, since leakage flow is proportional to $1 / \sqrt{N}$. Many combinations of depths and pipe diameters exceed what is capable by human input power. The corresponding flow rates for the data in Figure 3 are shown in Figure 4. While flow rate increases with increasing pipe diameter, so does the power requirement. A larger pipe diameter requires more power because of the greater volume of water being lifted through the pipe, which increases the force pushing down on the pistons. Note, for cases in Figure 3 where an input power is greater than $100 \mathrm{~W}$, this exceeds the input power constraint set at $100 \mathrm{~W}$. Thus, the critical velocity, $\mathrm{V}_{\mathrm{c}}$, is not achieved for the greater depths, larger pipe diameters, or fewer pistons per meter, and no flow occurs. Another trend related to Figures 3 and 4, which is not shown for a constant power, if pipe diameter were constant as depth increases, then flow rate would decrease and approach zero.

Representative experimental results for flow rate versus rotation rate of the crank are provided for the pump tests. Figure 5 shows experimental and theoretical results for flow rate when two pistons per meter are used and when the pump lifts water to a height of $5.2 \mathrm{~m}$ with a $2.54 \mathrm{~cm}$ pipe. Figures $6 \mathrm{~A}$ ) and B) show experimental and theoretical results when two pistons per meter are used and when the pump lifts to a height of $15.5 \mathrm{~m}$ with a $1.27 \mathrm{~cm}$ pipe, without or with the gears $(1.5: 1)$, respectively. The experimental results are between 3 to $18 \%$ less than the theoretical model predictions with greater differences when the rotation rate is greater. 


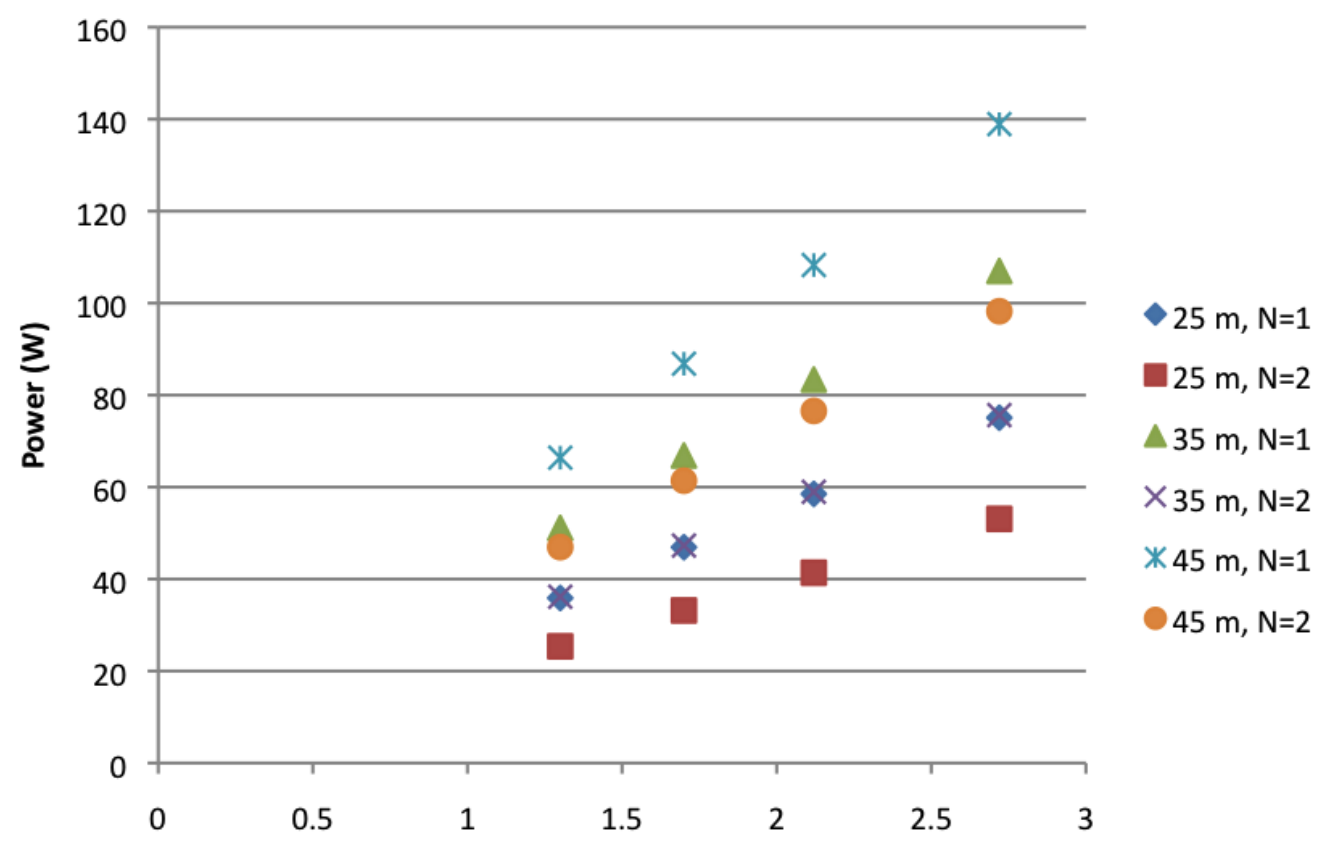

Pipe Diameter $(\mathrm{cm})$

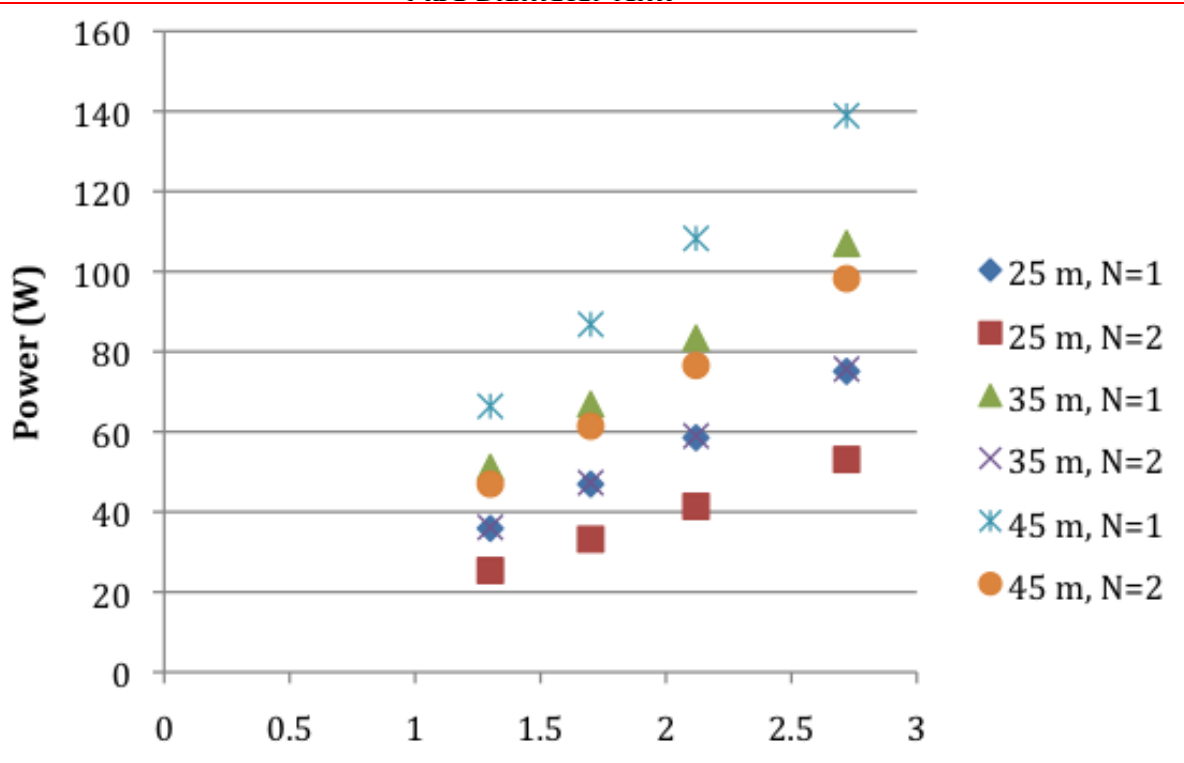

Pipe Diameter (cm)

FIGURE 3

Model Predicted Power Requirements for Various Depths (25 to 45 M), PiPe Diameters (1.3 TO 2.72 CM), Pistons PER METER ( $\mathrm{N}=1$ AND 2) FOR Piston Velocity OF 1.5 TIMES CRITICAL VELOCITY 

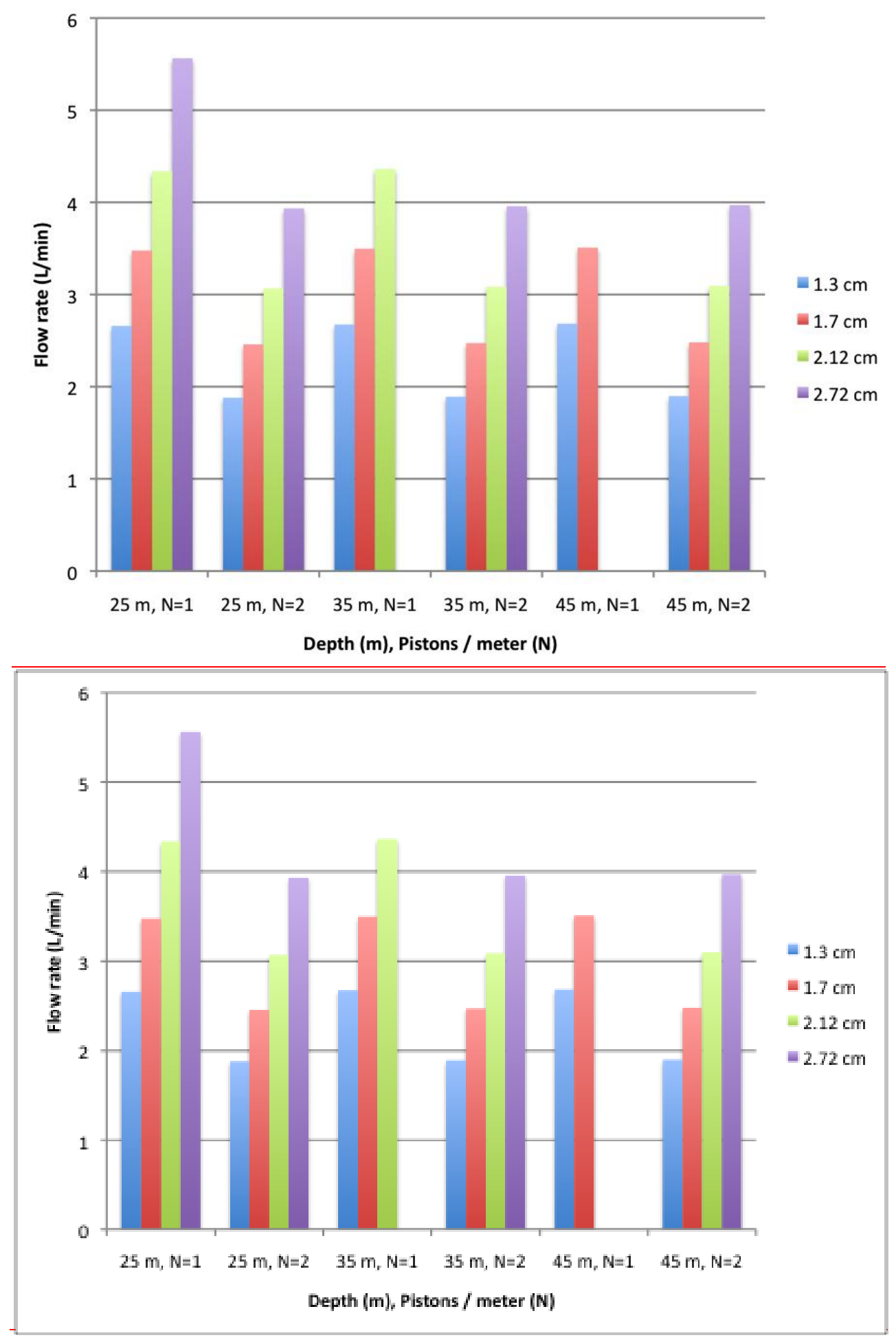

FIGURE 4

Model Predicted Flow Limitations for Various Depths (25 to 45 M), PiPe Diameters (1.3 TO 2.72 CM), PISTONS PER METER ( $\mathrm{N}=1$ AND 2) FOR PISTON VELOCITY OF 1.5 TIMES 
International Journal for Service Learning in Engineering Vol. 8, No. 2, pp. 8-23, Fall 2013

ISSN 1555-9033

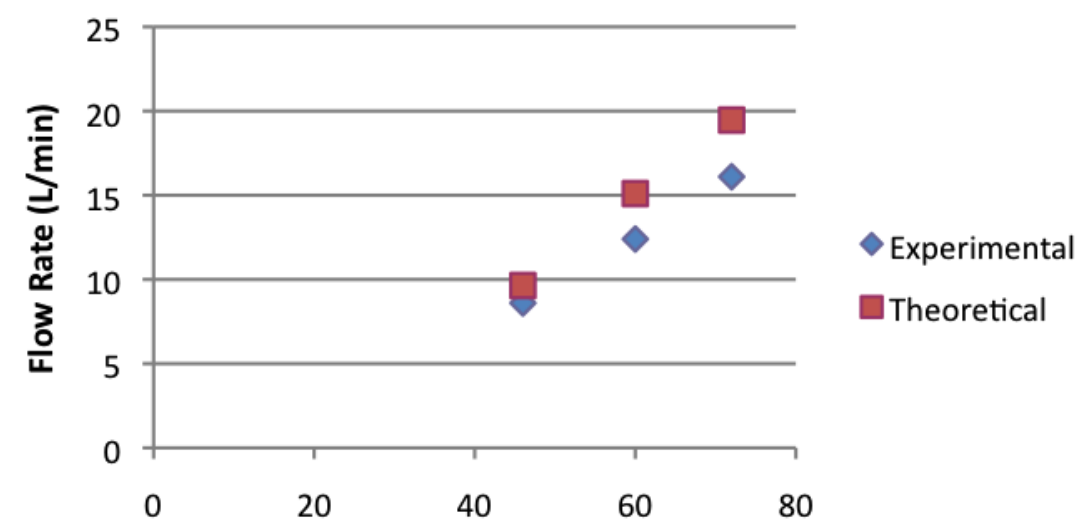

Rotations Per Minute

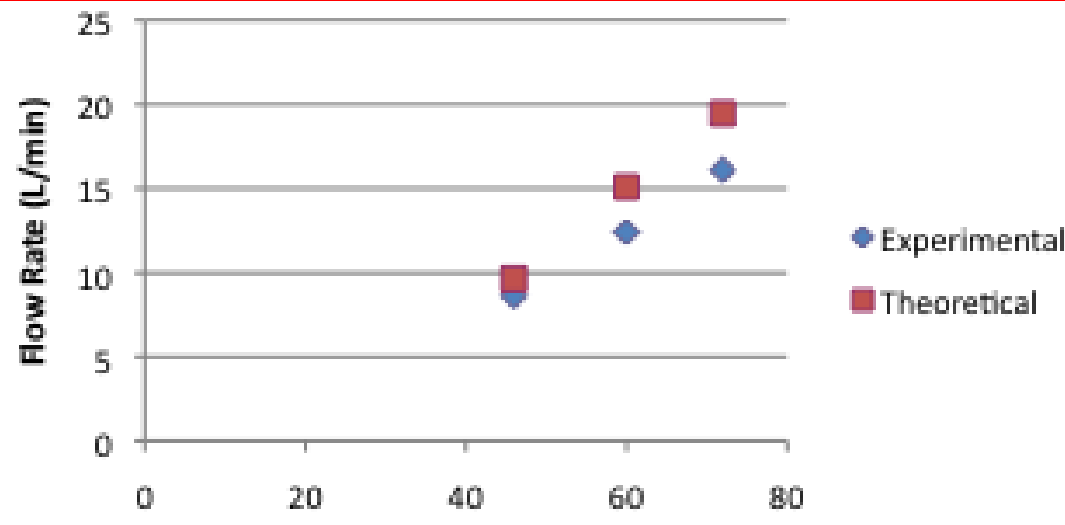

Rotations Per Minute

FIGURE 5

EXPERIMENTAL RESULTS AND MODEL PREDICTED FLOW RATES FOR PUMP HEIGHT OF $5.2 \mathrm{M}$ WITH 2.54 CM PIPE AND 2 PISTONS PER METER 


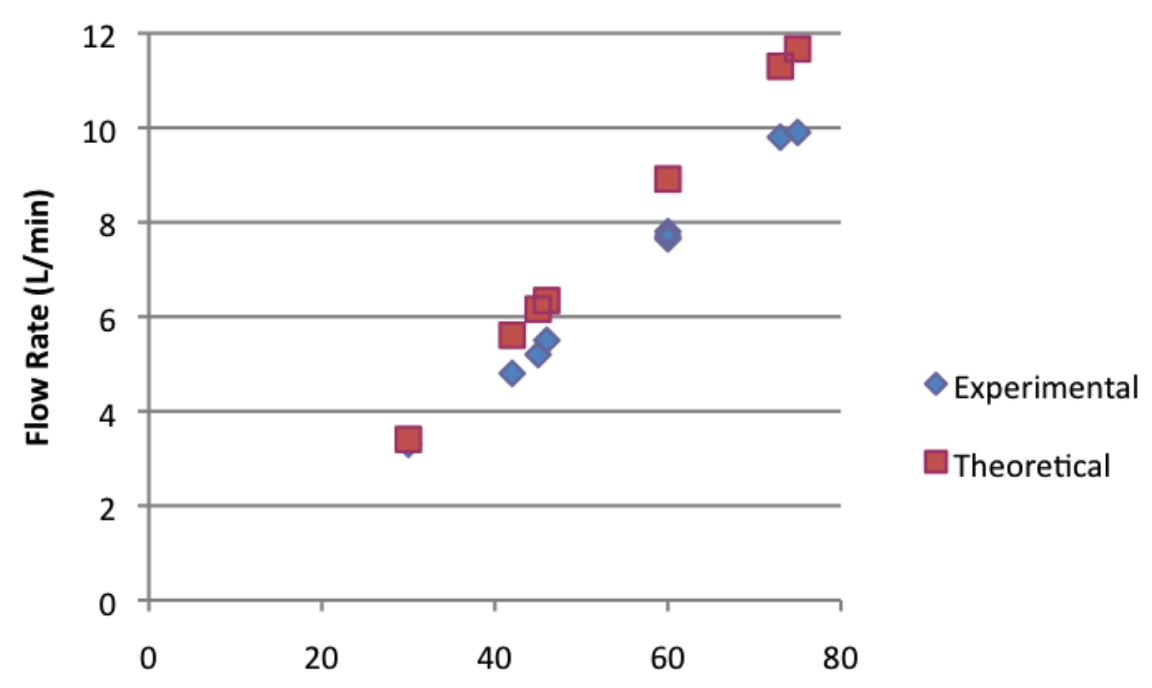

Rotations Per Minute

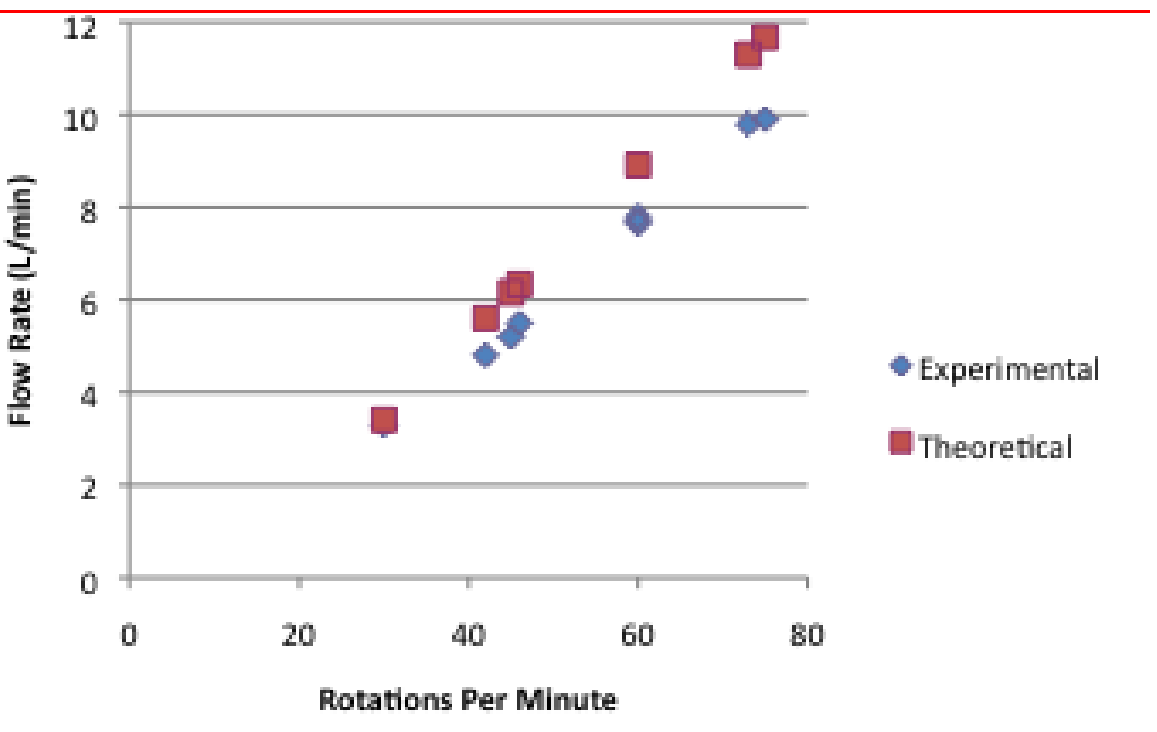

FIGURE 6A

EXPERIMENTAL RESULTS AND MODEL PREDICTED FLOW RATES FOR PUMP HEIGHT OF $15.5 \mathrm{M}$ WITH 1.27 CM PIPE AND 2 PISTONS PER METER A) WITHOUT AND B) WITH GEARS 

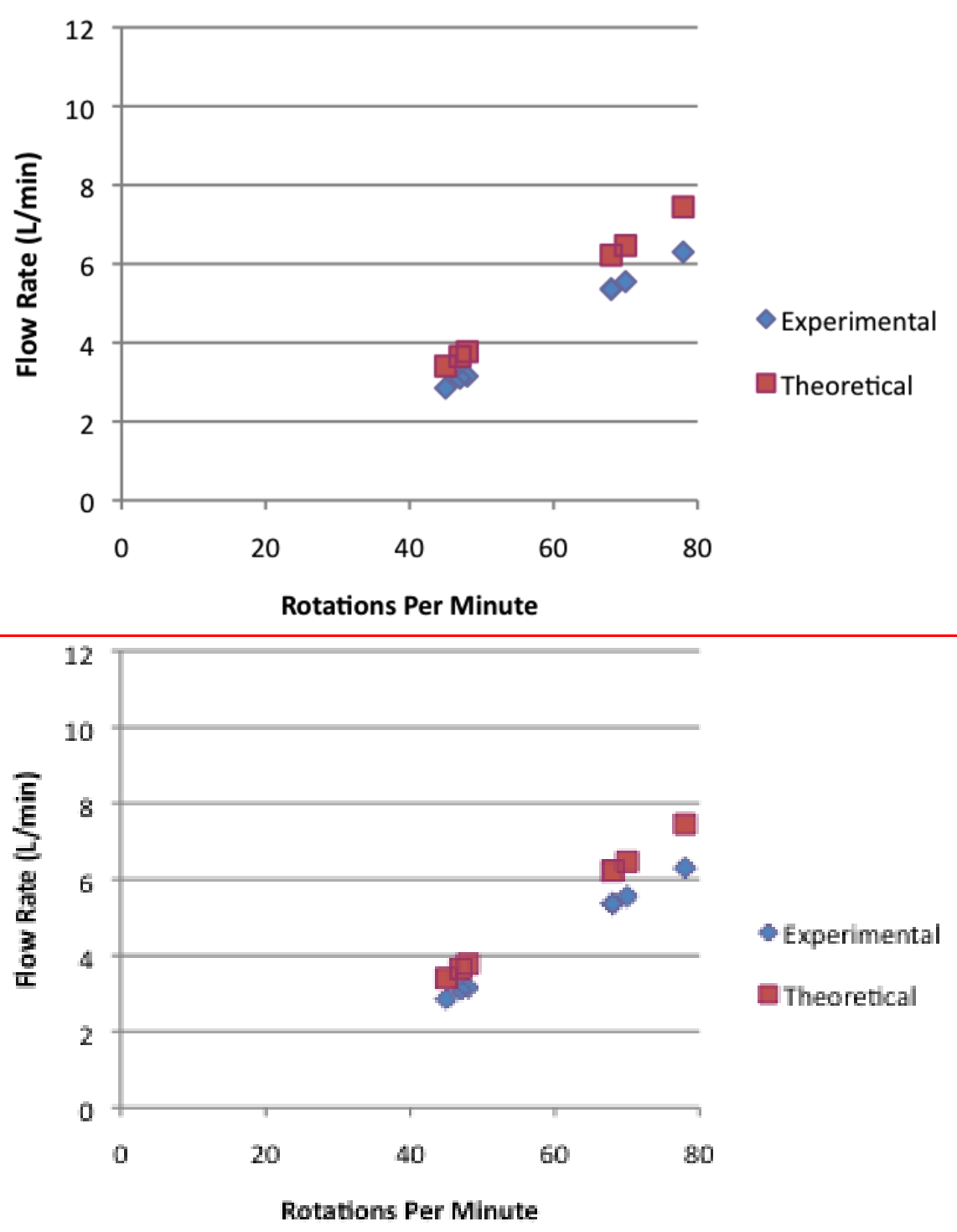

FIGURE 6B

EXPERIMENTAL RESULTS AND MODEL PREDICTED FLOW RATES FOR PUMP HEIGHT OF $15.5 \mathrm{M}$ WITH 1.27 CM PIPE AND 2 PISTONS PER METER A) WITHOUT AND B) WITH GEARS

Overall the studies showed that the model is accurate enough to use as a guide to construct a rope pump, which will perform at the depths of actual well levels, which is further discussed. 


\section{DISCUSSION}

The team successfully modeled and tested a rope pump to identify designs capable of lift depths of $35 \mathrm{~m}$ or more. The results show that the model provides a reasonable basis for predicting performance and designing rope pumps. The experimental flow rates were within 3 to $18 \%$ of that predicted, showing validity and utility of the model. One difference between model prediction and experimental results is due to the fact that the model does not take into account viscous effects, and mechanical friction losses exist when converting rotational motion into linear lifting of the pistons. Smulders and Rijs discuss ways to correct for viscous effects. ${ }^{\text {ix }}$ Frictional losses between mechanical components in the pump could be estimated or empirically determined to more accurately estimate the required pumping power. It was observed that at higher rotational speeds, some water tended to flow past the output spout and spill over the top of the pumping head, resulting in some water loss. This partly explains the greater percent difference between the experimental and theoretical results for higher rotation rates. As shown in Figure 2, the spout was modified with additional pipe at the top to recover some of the overflow into the main spout.

While the team did not have access to experimentally test depths of $35 \mathrm{~m}(\sim 100 \mathrm{ft})$, extrapolation of the $15.5 \mathrm{~m}$ results, the difference between experimental data and model predictions, and rope pump efficiency provide guidance for expected results at that depth. For example, Figure 3 shows that theoretically to attain flow of $2 \mathrm{~L} / \mathrm{min}$ approximately $35 \mathrm{~W}$ of power is needed for a depth of $35 \mathrm{~m}$, pipe diameter of $1.27 \mathrm{~cm}$ and $\mathrm{N}=2$ pistons $/ \mathrm{m}$ at critical velocity of $1.5 \mathrm{~V}_{\mathrm{c}}$. Using experimental results with a $20 \%$ difference from model prediction would result in a flow rate of $1.6 \mathrm{~L} / \mathrm{min}$ at $1.2 \mathrm{~V}_{\mathrm{c}}$. Taking into account an average efficiency of $67 \%$ for a rope pump to human effort into hydraulic discharge ${ }^{\mathrm{vi}}, 52 \mathrm{~W}$ of human power would be necessary. Thus, for a short time period - a few minutes, with a gearbox and $1.27 \mathrm{~cm}$ pipe diameter, retrieving water at $35 \mathrm{~m}$ depths using single human arm power with a rope pump is achievable. Use of the model, analysis and results provided could be used for other rope pump design situations. For higher desired flow rates or reaching greater depths additional power requirements would be necessary.

As previously mentioned, leg cranking (i.e. bicycle-like) provides greater human power than arms and the pump wheel can be modified to accommodate this solution. When implemented in The Gambia, women and children would generally use a rope pump. A cultural concern for a Gambian woman is to not expose her ankles. The most common attire for a woman is a grandmuba, which is a free flowing dress that covers up to their wrists and feet. ${ }^{\text {xiv }}$ Thus, a standard bicycle pump would be impractical in this situation. Future work could involve development of a leg crank design to minimize exposure and comfortably accommodate Gambian women. Other considerations may also be needed based on cultural norms of any region using a rope pump.

Another human powered pump considered was a merry-go round pump. This pump is heralded for its ingenuity and ability to incorporate a fun activity into a necessary task for children within the community. ${ }^{\mathrm{xv}}$ Limitations of the pump are that it needs to be run by multiple users at a time to work properly and may be cost-prohibitive in this situation. While the merrygo round pump may be a feasible solution, further investigation would be necessary. Design calculations provided in this document could provide guidance for implementation of such a solution. 
During the course of this project, a team of Rowan University students and a faculty member traveled to the Gambia in collaboration with students and faculty from the University of the Gambia as part of the Rowan-EWB efforts in the Gambia. The group traveled to eight villages in rural Gambia where they interacted with the villagers to provide recommendations to improve maintenance of water pumps and roads. ${ }^{\mathrm{xi}}$

\section{CONCLUSIONS}

As part of a capstone design course, a student team determined the feasibility of a human powered rope pump as a water retrieving solution at greater depth as requested by NGO client Paul Johnson of Concern Universal. The team first implemented a rope pump model and performed a parametric design study to determine the effect of pump parameters (pipe diameter, piston spacing, and input rotational speed). The students designed and built a rope pump, which is briefly described. The rope pump was tested for functional use, to compare experimental test results with model predictions and to make determinations about power requirements for reaching greater depths with human power. Experimental results were within $3-18 \%$ percent of model predictions for the experimental testing range, even when including a design modification to the waterspout to reduce overflow losses. Extrapolation of the results shows that the design problem was solved within the client specified constraints and briefly explores other solutions relevant to the context and environment of use. Further, this work provides design parameter guidance and quantitative results for greater reaching depths with a rope pump within the capabilities of human power that may be useful in rural and developing regions.

\section{ACKNOWLEDGMENTS}

The team thanks the Rowan University Venture Fund for financial support for this project. The team would like to thank former students Stephanie Camilo, Laura Thrall, Michael Schaffer, Joe Henderson and Paul Dietrick for their prior work on this project. The team thanks Mr. Paul Johnson and Dr. Kurt DeGoede for useful insights regarding this project. We thank Mr. Chuck Linderman, Mr. Kyle Fitzpatrick, Mr. Aaron Nolan, Mr. Marvin Harris and Prof. Skeffington Thomas for technical and fabrication assistance. We thank Dr. Hong Zhang, Sean Coffey, Gemma Peebles, and Andrea McFarland for recent travels to the Gambia for this project; and Dr. Momodou Jain and several students from the University of the Gambia for in-country support, project assistance and hospitality during that trip. Finally, thank you to reviewers, whose comments aided in improving this paper.

\section{REFERENCES}

\footnotetext{
${ }^{\text {i }}$ Paul Johnson, Personal Communication, Concern Universal, October 2, 2009.

${ }^{\text {ii }}$ S. Sutton and J. Gomme, "Transferring the Rope pump to Africa; A long and Winding road?", Waterlines. Vol: 28, April 2009

iii P.A. Harvey and T. Drouin, "The Case for the Rope Pump in Africa: A Comparative Performance Analysis," Journal of Water and Health. Vol. 4, p. 499-510, 2006

iv Practicafoundation.nl "Rope Pumps", www.practicafoundation.nl, (October 2008), accessed October 2009

${ }^{\mathrm{v}}$ http://www.rowan.edu/colleges/engineering/clinics/engwoborders/HTML/past.html
} 
${ }^{\mathrm{vi}}$ R.A. Lambert and R.D. Faulkner, "The Efficient Use of Human Energy for Micro-Scale Irrigation," J. of Agricultural Engineering Research. Vol 48, p. 171-183, Jan-Apr 1991

${ }^{v i i}$ H. Alberts, R Meza, D. Solis and M. Rodriguez, "How the rope pump won in Nicaragua," Waterlines 12(2), 3-5, 1993

${ }^{\text {viii }}$ H. Alberts, The rope pump: an example of technology transfer. Waterlines 22(3), 22-25 (2004)

${ }^{i x}$ P.T. Smulders and R.P.P Rijs. "A Hydrodynamic Model of the Rope Pump,” ( ) The Netherlands, 2006

${ }^{\mathrm{x}}$ Manual 15e Build a simple rope pump. (n.d.)., from Gaia movement: http://www.gaia-movement.org, accessed September 2010

${ }^{x i}$ S. Camilo, J. Henderson, M. Schaeffer, L. Thrall, "Rope Pump Design Project”, Rowan University, December 2010

xii P. Dietrick, J. Henderson, "Rope Pump Design Project", Rowan University, May 2011

${ }_{\text {xiii }}$ T. Purdue, K. Dmitruck, K. Ketcho, K. Pillion, "Rope Pump Design Project”, Rowan University, December 2011

${ }^{x i v}$ Gambian Culture, Society and Traditions. from Access Gambia: http://www.accessgambia.com, Retrieved December 8, 2011

${ }^{x v}$ Kain, A. (2009, May 3). Top 6 Designs That Harness the Power of Play. Retrieved December 18, 2010, from InHabitots: http://www.inhabitots.com/play-pump-the-merry-go-round-waterpump/

${ }^{x v i}$ H. Zhang, J. Everett, J. Kadlowec, S. Coffey, A. McFarland. "From Glassboro to The Gambia- A Collaborative Work with the University of the Gambia and a Winter Trip to the Gambia Villages", Proc. ASEE Annual Conf., Atlanta, GA, 2013 